\title{
Effect of finger interaction on individual finger: index finger
}

\author{
Yong-Ku Kong, Min-Tae Seo, Hyun-Sung Kang and Dae-Min Kim* \\ Industrial Engineering, Sungkyunkwan University, Suwon, 440-746, South Korea
}

\begin{abstract}
Grip strength is affected by such as enslaving effect, force sharing effect, and force deficit effect relating to the interaction among fingers. The author attempts to analyze index finger strength according to grip span of adjacent middle finger. 6 male graduate students participated as subjects in this experiment. The grip span has been applied from $45 \mathrm{~mm}$ to $60 \mathrm{~mm}$ to investigate the effects of a coordination of grip spans on the index and middle finger strength. Results showed that index finger strength was the smallest in case of index finger grip span of $45 \mathrm{~mm}$. Index finger strength decreased as the middle finger grip span. In general index finger strength shared a decreasing trend when the grip span of the middle finger increased. This study has an implication that the grip span of index and middle fingers influences force sharing effect on index finger.
\end{abstract}

Keywords: Grip strength, Finger forces, MFFM system

\section{Introduction}

A human hand consists of 8 carpal bones, 5 metacarpal bones, and 14 metacarpal bones. Each bone is connected with joint, which makes hand movement free. Human uses hands freely to do a variety of activities. There have been numerous studies on hand grip strength[1][2][3][4], where subjects anthropometry and physical characteristics(handle grip span, handle shape and handle material etc.) of grip strength measurement device have an effect on study results[1][5][6][7]. Furthermore, the studies on finger force have been researched in various ways such as experiment of finger force, and predicting finger force by theoretical models [7][8][9][10][11][12][13] [14]. Grip strength is affected by such various effects as enslaving effect, force sharing effect, and force deficit effect relating to the interaction among fingers[7][12][15][16]. Studies on interaction among fingers by numerous variables based upon experimental approaches have been conducted.

Previous research findings showed that index finger strength shaved a decreasing trend when the grip span of the middle finger increased [7]. The main purpose of this study was to investigate the effects of the grip spans of fingers on the index finger strength.

\section{Methods}

A total of 6 subjects participated in the experiments. Subjects were graduate students who did not experience any musculoskeletal disorders in their upper limbs.

This study used an MFFM system which was developed by this research group to measure the individual and total finger forces for various grip spans [17]. Each subject sat up straight on a chair and maintained his elbow at $90^{\circ}$ and wrist at $0^{\circ}$ when exerting a maximum gripping force by squeezing each handle shape. This study changed the grip span between index and middle fingers to measure the grip strength of each finger according to 25 types of grip span in total (Table 1). The grip spans of ring and little fingers were the same as the grip span of middle finger over all 25 of handle type to minimize the effects of other fingers' coordination on the index and middle finger forces. The subjects were asked to repeat the exertions one times for each shape. Thus

This work was supported by National Research Foundation of Korea(NRF) grant funded by the Korea government (MEST) (No. 20110016753)

${ }^{*}$ Corresponding author: Dea-Min Kim. E-mail: neojewel@lycos.co.kr. 
each subject randomly performed a total 25 trials and a 3-minute recess was allowed between trials.

The dependent variables of the study were the index finger force. SPSS (SPSS 18.0) was used for the descriptive statistics and the analysis of variance (ANOVA) with a $2 \times 2$ between subjects design of grip span (index and middle) as the independent variables.

Table 1. 25 types of grip span

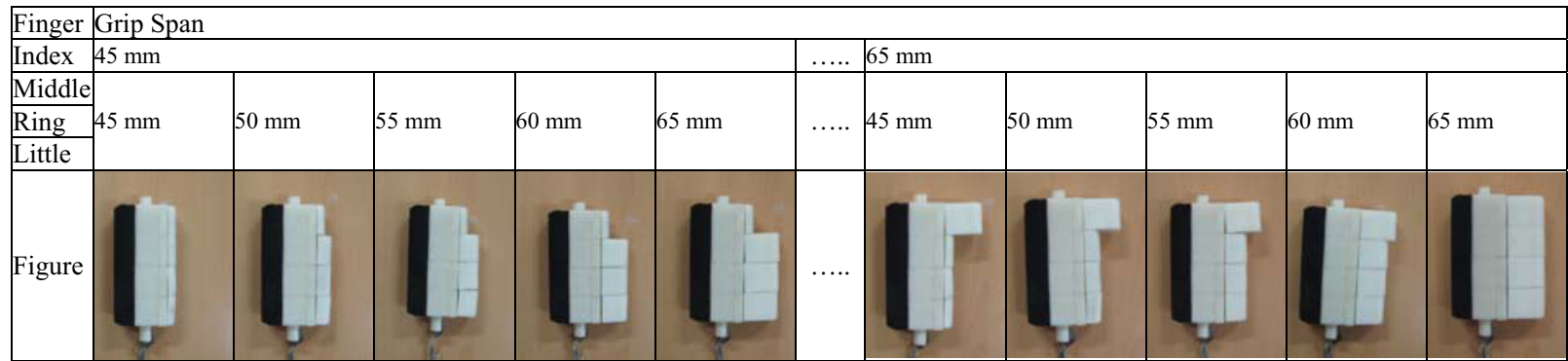

\section{Results}

Then the force exerted by index finger was analyzed in accordance with grip span of index and middle finger. The result of the analysis was statistically significant in respect to the index finger force, exhibited statistical significance in proportion to the index and middle finger grip span. As shown in Table 2, illustrates the contribution of force exerted by fingers according to index and middle finger grip span to the grip, and the symbols of alphabet on each column demonstrates the Tukey test results.
If the grip span of middle finger is decreased more than the grip span of index finger in comparison with the handle of both fingers' grip spans, index strength is increased, and if the grip span of the middle is increased more than the index grip span, the index strength is decreased. For example, in the same handle (55-55-55-55) that the grip span of the index finger is $55 \mathrm{~mm}$ and the grip span of the middle finger is $55 \mathrm{~mm}$, index finger strength becomes $67.0 \mathrm{~N}$. If in this handle the grip span of the middle finger is increased in $60 \mathrm{~mm}$ and $65 \mathrm{~mm}$, the index finger strength is decreased in $63.3 \mathrm{~N}$ and $51.9 \mathrm{~N}$ respectively. If it is also decreased in $50 \mathrm{~mm}$ and $45 \mathrm{~mm}$, it is confirmed that the index finger strength is increased in $82.1 \mathrm{~N}$ and $89.2 \mathrm{~N}$ respectively.

Table 2. Results of index finger force

\begin{tabular}{|c|c|c|c|c|c|c|c|}
\hline \multirow{2}{*}{\multicolumn{2}{|c|}{ Index finger force }} & \multicolumn{6}{|c|}{ Middle finger grip span } \\
\hline & & $45 \mathrm{~mm}$ & $50 \mathrm{~mm}$ & $55 \mathrm{~mm}$ & $60 \mathrm{~mm}$ & $65 \mathrm{~mm}$ & average \\
\hline \multirow{6}{*}{$\begin{array}{l}\text { Index } \\
\text { finger } \\
\text { grip span }\end{array}$} & $45 \mathrm{~mm}$ & $62.4^{\mathrm{A}}$ & $45.2^{\mathrm{AB}}$ & $46.2^{\mathrm{AB}}$ & $33.9^{\mathrm{B}}$ & $30.9^{\mathrm{B}}$ & $43.7^{b}$ \\
\hline & $50 \mathrm{~mm}$ & $86.5^{\mathrm{A}}$ & $70.9^{\mathrm{AB}}$ & $58.9^{\mathrm{AB}}$ & $51.0^{\mathrm{B}}$ & $43.0^{\mathrm{B}}$ & $62.1^{\mathrm{a}}$ \\
\hline & $55 \mathrm{~mm}$ & $89.2^{\mathrm{A}}$ & $82.1^{\mathrm{A}}$ & $67.0^{\mathrm{A}}$ & $63.3^{\mathrm{A}}$ & $51.9^{\mathrm{A}}$ & $70.7^{\mathrm{a}}$ \\
\hline & $60 \mathrm{~mm}$ & $74.9^{\mathrm{A}}$ & $73.0^{\mathrm{A}}$ & $73.7^{\mathrm{A}}$ & $66.8^{\mathrm{A}}$ & $49.3^{\mathrm{A}}$ & $67.5^{\mathrm{a}}$ \\
\hline & $65 \mathrm{~mm}$ & $68.3^{\mathrm{A}}$ & $69.5^{\mathrm{A}}$ & $71.2^{\mathrm{A}}$ & $66.8^{\mathrm{A}}$ & $65.5^{\mathrm{A}}$ & $68.3^{\mathrm{a}}$ \\
\hline & average & $76.3^{\mathrm{A}}$ & $68.1^{\mathrm{AB}}$ & $63.4^{\mathrm{B}}$ & $56.4^{\mathrm{BC}}$ & $48.1^{\mathrm{C}}$ & \\
\hline
\end{tabular}

(Alphabet means significant grouping in statistics, $\mathrm{A}=$ Tukey test results of index finger forces for Middle finger grip span, $\mathrm{a}=$ Tukey test results of index finger forces for index finger grip span, Index finger force, unit: N) 


\section{Discussion}

Regarding index finger strength according to middle finger grip span, index finger strength had a tendency of decrease as the increase of middle finger grip span, which was statistically significant. In particular, middle finger grip span of $45 \mathrm{~mm}$ led to the greatest level $(76.3 \mathrm{~N})$ of index finger strength, whereas grip span of $65 \mathrm{~mm}$ led to the smallest $(48.1 \mathrm{~N})$ strength.

In addition, index finger strength had a tendency of decrease as the increase of middle finger grip span in same grip span of index and middle finger. When the task needs strength of index finger to gain an effective functionality, it is preferred that longer index grip span than middle one, or the same grip span of index and middle finger at least.

According to previous literature, there exists interactive association between fingers in case of force by multiple fingers [15]. And there are papers on various experimental conditions such as enslaving effect, force sharing effect, and force deficit effect of neural command[12][15][16]. Force sharing effect means the division of finger force in specific ratio. This study has an implication that the grip span of index and middle fingers influences force sharing effect on index finger. Although this study has a few limitations, the author expects to develop a prediction model on finger strength by considering such effects in further study by complementing such short comings.

\section{References}

[1] S. T. Pheasant, and J. G. Scriven, Sex differences in strength Some implications of the design of handtools, Proceeding of the Ergonomics Society's Annual Conference, 9-13, 1983.

[2] J. Blackwell, K. W. Kornatz, and E. Heath, Effect of grip span on maximal grip force and fatigue of flexor digitorum superficialis, Applied Ergonomics, 30, 401-405, 1999.
[3] Y. Kong, and A. Freivalds, Evaluation of meat-hook handle shapes, International Journal of Industrial Ergonomics, 32, 1323, 2003.

[4] Y.K. Kong, A. Freivalds and S.E Kim, Evaluation of hook handles in a pulling task. International Journal of Occupational Safety and Ergonomics, 11(3), 303-313, 2005.

[5] J. Petrofsky, C. Williams, G. Kamen, and A. Lind, The effect of handgrip span on isometric exercise performance, Ergonomics, 23(12), 1129-1135, 1980.

[6] M. Eksioglu, Relative optimum grip span as a function of hand anthropometry, International Journal of Industrial Ergonomics, 34, 1-12, 2004.

[7] Y.K. Kong, D.M. Kim, K.S. Lee and M.C. Jung, Handle shape evaluation for young and old age groups using the Multi-Finger Force Measurement(MFFM) system, International Ergonomics Association(IEA) $17^{\text {th }}$ World Congress on Ergonomics, Beijing, 9-14 August, 2009.

[8] J. M. F. Landsmeer, Studies in the anatomy of articulation. part 1: The equilibrium of the intercalated bone, Acta Morphological Neerlando Scandinavica, 38, 287-303, 3, 1961a.

[9] J. M. F. Landsmeer, Studies in the anatomy of articulation. part 2: patterns of movement of bi-muscular, bi-articular system, Acta Morphologica Neerlando Scandinavica, 38(3), 304321, $1961 \mathrm{~b}$.

[10]K. N. An, E. Y. Chao, W. P. Cooney and R. L. Linscheid, Normative model of human hand for biomechanics analysis, Journal of Biomechanics, 12, 775-788, 1979.

[11] K. N. An, Y. Ueba, E. Y. Chao, W. P. Cooney and R. L. Linscheid, Tendon excursion and moment arm of index finger muscles, Journal of Biomechanics, 16(6), 419-425, 1983.

[12] V.M. Zatsiorsky, Z.M. Li and M.L. Latash, Enslaving Effects in Multi-Finger Force Production. Experimental Brain Research, 131, 187-195, 2000.

[13] J. Z. Wu, R. G. Dong, T. W. McDowell and D. E. Welcome, Modeling the finger joint moments in a hand at the maximal isometric grip: The effects of friction. Medical Engineering \& Physics, 2009.

[14] J. Z. Wu, K. N. An, R. G. Cutlip, R. G. Dong, A practical biomechanical model of the index finger simulating the kinematics of the muscle/tendon excursions, Bio-Medical Materials and Engineering, 20, 89-97, 2010.

[15]Li, Z. M., Latash, M. L., et al., V. M., Motor Redundancy during Maximal Voluntary Contraction in Four-Finger Tasks. Experimental Brain Research, 122, 71-78, 1998.

[16]F. Danion, G. Schoner, M. Latash, S. Li, J. P. Scholz and V. M. Zatsiorsky, A Mode Hypothesis for Finger Interaction during Multi-finger Force-Production Tasks. Biological Cybernetics, 88, 91-98, 2003

[17]D.M. Kim and Y.K. Kong, Development of an Adjustable Multi-Finger Force Measurement (MFFM) System for research on hand tool-related musculoskeletal disorders. Applied Human Factors and Ergonomics 2nd international conference, Las Vegas, 14-17 July, 2008 